\title{
A Comparative analysis of Intersectionality under Discrimination Law in the Light of Vulnerability Theory as a Post-Identity Approach
}

Shwetank Sharma*

\begin{abstract}
In spite of the presence of intersectionality as a concept in feminist literature for over twenty-five years, the State Policy, across the world, has been ignorant towards the interplay of identities and its role in the discrimination law jurisprudence. This article claims that a legitimate accommodation of a multi-ground claim under the Right to Equality regime, present in various legal systems, shall be a purposive step towards substantive equality. The article also highlights certain frailties associated with Intersectionality and introduces the age-old dilemma surrounding the formulation of State Policy, as to whether it should be "identity-neutral" like anti-classification principle, or "identity-sensitive" like intersectionality itself. The article also introduces the vulnerability theory proposed by Martha Fineman, as a post identity approach. The final analysis, explains how the two theories can coexist so that the State Policy can move towards substantive equality, and thus, mitigate the horrors of discrimination.
\end{abstract}

Keywords: Discrimination, Equality, Identity, Intersectionality, Vulnerability

*Amity Law School, Noida, India; sharmashwetank17@hotmail.com 


\section{Introduction}

This article seeks to understand how identities play a seminal role in and around the development of discrimination law jurisprudence, across the world. The aim is to examine how the identity of an individual in isolation and coupled with his other identities provides for an inter-sectional claim, and most importantly, to assess the reception of such claims by the adjudicating courts. The article looks into claims made under various jurisdictions and how an inter-sectional claim still struggles to find its ground, even after being around for more than 25 years in the legal literature. The paper, initially deals with an inquiry into how discrimination laws have confined their application to singular claims arising out of discrimination based on one of the listed grounds and have failed to recognize a claim arising out of various grounds, due to an inter-play of various identities of an individual. For instance, a Muslim woman can face discrimination due to her sex as well as due to her religion. Therefore, she would share experiences of discrimination with Hindu women, as well as with Muslim men. Then again, she would have certain unique experiences by virtue of her being a 'woman' and a 'Muslim'.

The interpretation of the discrimination laws has foreclosed the routes to recognize such claims of intersectional discrimination. This paper also takes examples of experiences of Black women in the United States of America, among others, to analyze qualitatively, a quantitative sense of a multi-ground claim. ${ }^{1}$ Further, the article addresses and acknowledges various limitations to an identity-approach towards discrimination laws, and how identity-based studies of discrimination have quintessentially; put the objective of ensuring equality on the wayside of equality laws. The article then puts forward the 'vulnerability theory', developed by Martha Fineman', as an alternative framework for understanding substantive equality, which ordains a positive and

1 Kimberle Crenshaw, Demarginalizing the Intersection of Race and Sex: A Black Feminist Critique of Antidiscrimination Doctrine, Feminist Theory and Antiracist Politics, 4 U. Chi. L. Rev. (1989). [Crenshaw]

2 Martha A Fineman, The Vulnerable Subject: Anchoring Equality in the Human Condition, 20 Yale J.L. \& Feminism 1, 9-15 (2008). [Fineman] 
determined role of a welfare state. The paper concludes by addressing the flaws of such post-identity approaches and by advocating the need for revising the theory and concept of interdependence. A strong 'paternalistic' state coupled with 'intersectionality' can be a useful construct to design social policy, is the strong contention put forth by the author.

\section{Intersectionality Theory}

"A race was not fair if one runner left the starting line three hundred years before the other". 3

Martin Luther King Jr. used this metaphor to make the Americans understand the plight of the victims of racial discrimination, and how it is imperative to bring the historically disadvantaged subjects of the State, to the same pedestal as of those who haven't faced such discriminatory practices. The conversation around discrimination and the jurisprudence behind it begins from this context.

The history of citizens and their groups are innately linked to discriminatory practices either deployed by them or on them. This discrimination and injustice caused is based on various identities like religion, language, gender, caste, etc. ${ }^{4}$ Such historical disadvantages and disabilities associated with certain members of our society has been substratum of the discrimination law jurisprudence in and around the world. As an individual living in a social environment and being an integral part of the social order, we tend to acquire various identities. Discrimination laws in all the jurisdictions are anchored on our identities.

Our daily experiences are creatures of interplay between these identities. Though the modern world has accepted the existence of several identities in one person the ramifications of such multiple identities have not been translated into the interpretation of discrimination laws across the world. When we use terms such as a

${ }^{3}$ MARTIN LUTHER KING, JR., WHY WE CAN'T WAIT, 147 (Penguin USA, 2002).

${ }^{4}$ Abhiram Singh v. C.D Commachen (Dead) by Lrs. \&Ors, 2017 SCC OnLine SC 9. 
"Black Lesbian" or a "Poor Muslim Woman" there is a symbiosis of several identities of that person. A 'Black Lesbian' at one point of time belongs to the community of Black persons as well as to the Lesbian Gay Bisexual Transgender Queer (LGBTQ) community. At the same time, she forms a part of a distinct set of "Black Lesbians", who shall have isolated experiences by virtue of such a unique permutation of identities. Similarly, a 'poor Muslim woman' can identify herself as being poor, a Muslim by religion, and a woman by her gender, thereby experiencing the world from each of the single axes, yet forming a new identity by virtue of the existence of these three identities in one person. The recognition of such a distinction in gender politics seems to be amiss from the interpretation of discrimination laws by the courts today.

Intersectionality is an approach to analyze an individual's identity. It recognizes the fact that different identity categories can intersect and co-exist in the same individual in a way which creates a qualitatively different experience, when compared to any of the individual characteristics involved. ${ }^{5}$ Kimberlé Crenshaw, who coined the term, used experiences of 'Black women' to explain how the 'single axis' model of identity and the 'anti-racist' campaigns in the U.S.A. have failed them as their unique sufferings were silenced by the dominate narrative of 'race' and 'sex', individually. ${ }^{6}$ Intersectionality, as a principle denies that identity can be dissected into "mutually exclusive categories of experience and analysis" 7 . The theory comes into play where one identity marker viz. race, caste, gender, etc. interacts with another identity marker, giving rise to a distinct experience of discrimination against the subject. However, if individual markers are observed, they only highlight independent instances of discrimination. Therefore, when discrimination is faced in the former form, that experience of dual minority, has not been recognized by Courts, nor can there be seen a provision for any remedy under law. ${ }^{8}$

5 Ben Smith, Substantive Equality: A Comparative and Theoretical Perspective, 16 Equal Rights Review 73, 73 (2016).

${ }^{6}$ Crenshaw, supra note 1.

${ }^{7} I d$ at 139.

8 Id at 150. 


\section{1 Types of Multiple Ground Claims}

It is important to distinguish an intersectional claim from other types of multiple ground claims. Generally, there are three ways in which an individual can suffer discrimination. The first is when an individual suffers discrimination on different grounds on separate occasions. For instance, a person from a Scheduled Caste with a disability, might on one occasion experience discrimination due to his caste, and at some other occasion face discrimination due to his disability. Each incident can be assessed on a single ground and compensation can be awarded accordingly. This type of discrimination is called 'sequential multiple discrimination. ${ }^{9}$ It reflects hegemonic discourses of identity politics that disregards the invisible experiences of the marginalized members of a specific social category and constructs a homogenized 'right way' to be the practiced rule. ${ }^{10}$ A second manifestation occurs when a person is discriminated against on the same occasion, but in two different ways. This type of discrimination occurs when a person is discriminated against on more than one ground in the same instance and thus, the discrimination faced by the individual on each ground gets compounded. This creates an additional burden. ${ }^{11}$ For example, a gay woman might claim that she has been subject to harassment both because she is a woman and because she is gay at the same time. This kind of discrimination is called 'additive discrimination' as each of the constituent discriminatory instances gives rise to an independent cause of action as the person has been subjected to discrimination on both grounds simultaneously.12 An

9Sandra Fredman, Intersectional discrimination in EU gender equality and nondiscrimination law, EUROPEAN COMMISSION, 27 (Mar. 29, 2017, 10:00 AM), http://ec.europa.eu/justice/gender-equality/ document/ files/ intersectionality.pdf. [Fredman]

10 N. Yuval-Davies, Intersectionality and Feminist Politics, 13 EUR. J. WOMENS STUD, 195 (2006).

${ }^{11}$ Carles, I., Jubany-Baucells, O., GendeRace - The Use of Racial AntiDiscrimination Laws: Gender and Citizenship in a Multicultural Context, 72 (Nov. 27, 2017, 9:35 PM)http:// genderace.ulb.ac.be/ rapports/ GENDERACE\%20FINAL\%20REPORT\%20sent.pdf.

${ }^{12}$ Fredman, supra at 7. 
example can be found in Perera v. Civil Service Commission, ${ }^{13}$ in which the appellant had contended discrimination by the recruitment policy of the respondent, based on grounds of nationality, age and command over the English language. This is considered to be an additive form of discrimination as each ground made it less likely for the appellant to get a job. Though additive discrimination includes multiple grounds of discrimination, the independent and mutually exclusive nature of such protected grounds is maintained intact.

The third type is different to the aforementioned kinds of multiground discrimination, in the sense that it is not merely a sequential addition of two discriminatory grounds, but rather the resultant discrimination is 'synergistic'. ${ }^{14}$ This subject is known as the 'Intersectional theory'. Intersectionality tries to explain how interaction of all identities of an individual tends to create a complex identity. For example, Crenshaw cites De Graffenreid $v$. General Motors Assembly Division ${ }^{15}$, to explain intersectional discrimination. In this case, five black women, being the most recent entries to the company, were made redundant first. Since white women and black men were among those who escaped redundancy, the black women complainants could not claim that they had been less favorably treated on grounds of either gender or race alone. It was only because they were both black and female that they were discriminated against. ${ }^{16}$ White women may face sexism but can be beneficiaries of racism and conversely, black men may be victims of racism but perpetrators of sexism. It is only the separate class of 'black women' that faces both forms of discrimination, at the same time.

\section{2 Horizontal Inequalities and Intersectionality}

Horizontal inequalities are, primarily, inequalities among culturally defined (or constructed) groups marked by specific

13Perera v. Civil Service Commission, [1983] IRLR 166.

${ }^{14}$ Crenshaw, supra at139.

15 DeGraffenreid v. General Motors Assembly Division, 413 F Supp. 142 (US Federal Court of Appeals). [DeGraffenreid]

${ }^{16}$ Fredman, supra at 28. 
identities, like gender, race, ethnicity or religion. It is in contrast to the concept of vertical inequality which deals with inequalities amongst individuals. This theory was developed by Francis Stewart.

The sort of groups we are discussing here are ethnic groups - where history, language, symbols and behavior differentiate people; immigrant groups, differentiated by history, and sometimes by physiology, language, etc.; racial groups, differentiated by physiology, history and sometimes language, and religious groups, differentiated by adherence to particular beliefs and membership into religious institutions. In each case, the boundaries are often unclear; in each case, people can sometimes change membership (particularly in the case of religion); yet in each case, there are recognized markers that differentiate people. ${ }^{17}$

Vertical inequalities have been justified as necessary for competition and allocational efficiency. Horizontal inequalities have proved to be a handicap, because they are beyond an individual's control. There are also reasons to believe that an increase in the number of horizontal inequalities have a significant impact on the increase in violence and conflicts. ${ }^{18}$ Francis Stewart gives examples of Blacks in the US, Northerners in Ghana and Aborigines in Australia, where individuals may improve, but the group as a whole, rarely does. Like intersectionality, horizontal inequalities also are premised on identities, unlike vertical inequalities. Therefore, there seems to be a legitimate overlap. However, horizontal inequalities tend to be similar to intersection of dimensions of deprivation, such as a group being deprived

17 Frances Stewart \& Arnim Langer, Horizontal Inequalities: Explaining persistence and change, CRISE (Oct. 23, 2017, 2:28 PM) http:// citeseerx.ist.psu.edu/viewdoc/download?doi=10.1.1.559.1632\&rep=rep1 \&type $=$ pdf.

${ }^{18}$ Frances Stewart, Horizontal inequalities as a cause of conflict, UNIVERSITY OF BRADFORD (Oct. 23, 2017, 3:00 PM) https:// www.bradford.ac.uk/ social-sciences/ media/ socialsciences/ BDLStewart.pdf. 
simultaneously in both political and economic dimensions. So, with horizontal inequalities, there is a special emphasis on dimensional intersectionality as, for a group, only one identity functions as being the point of commonality within the group.

Intersection of disadvantaged or advantaged identities occurs as a consequence of every person having multiple identities. Empirical investigation with respect to horizontal inequalities have identified intersecting horizontal inequalities of this kind - notably that women in marginalized groups typically form the most deprived category. ${ }^{19}$ However, till date not a great deal of emphasis has been put on this type of intersection in horizontal inequalities, since the aim has been to identify the consequences of horizontal inequalities for social stability and cohesion, not to identify group characteristics of the most deprived individuals. However, the intersection of identities- such as being a woman and a slave, finds lesser relevance in discourses around horizontal and vertical inequalities than dimensional intersectionality.

Dimensional intersectionality is of more relevance to the persistence of horizontal inequalities because, deprivation (or privilege) in a range of dimensions reinforce deprivation in each individual dimension and deprivation overall (or privilege). ${ }^{20}$ In spite of its similarity, there are two differences in intersectionality and horizontal inequality approach. Firstly, Intersectionality focuses on finding intersection of identities and how such intersections create disadvantage. Horizontal inequality approach, on the other hand, looks for causes and consequences of such horizontal inequalities which are a reason for conflict and social cohesion. Secondly, horizontal inequality approach tends to look at identities/dimensions which are likely to be provocative, while intersectionality looks at identities, for example - income, which affects personal well-being too. ${ }^{21}$ However, the policy approach to

19 Francis Stewart, Horizontal inequalities and intersectionality, MAITREYEE E-BULLETIN OF THE HUMAN DEVELOPMENT \& CAPABILITY ASSOCIATION, (Oct. 26, 2017, 03:00 PM), https:// www.odi.org/ sites/ odi.org.uk/files/odi-assets/publications-opinion-files/9173.pdf

${ }^{20} \mathrm{Id}$ at 11

${ }^{21}$ Id at 12 
these two theories is similar, if not identical. Both methods put emphasize on removing discrimination, and highlight the significance of affirmative action. The author suggests that while the inequality approach would be particularly concerned with correction of group horizontal inequality as a whole, intersectionality would be more concerned with categories that are deprived due to intersection of identities.

\section{3 Application of Intersectionality theory by Courts in various jurisdictions}

\section{3(i) United States of America (US)}

One of the most famous examples of the US Courts applying single axis models was Geduldig v. Aiello22, where courts did not recognize an intersectional discrimination of a pregnant woman based on her gender and pregnancy, but rather, found that discrimination on the basis of pregnancy did not constitute discrimination on the basis of gender, but merely a distinction between pregnant and nonpregnant women.

Apart from the case noted above ${ }^{23}$, Crenshaw discusses two other cases brought under Title VII of the Civil Rights Act, 1964, that is, Moore v. Hughes Helicopter Inc. ${ }^{24}$ (hereinafter "Moore") and Payne v. Travenol Laboratories Inc. ${ }^{25}$ (hereinafter "Payne"). In Moore, a black woman alleged discrimination by Hughes Helicopters Inc., during selection of employees for superior positions. In the suit, Moore had requested the case to be converted into a class action, on behalf of all female employees, but this plea was categorically rejected by the court because, as a Black female, she could not represent white women. Therefore, the discrimination brought forth could not be considered by the court as one of sexual discrimination.

In Payne, Black female workers had brought a class action against the respondent company that had recruited them for positions that had a low pay. The court accepted the racial discrimination plea of

\footnotetext{
${ }^{22}$ Geduldig v. Aiello, 417 U.S. 484, 496 n.20 (1974).

${ }^{23}$ DeGraffenreid,supra note 13.

24 Moore v. Hughes Helicopter Inc., 708 F.2d 475 (9th Cir. 1983).

25 Payne v. Travenol Laboratories Inc., 673 F.2d 798 (5th Cir. 1982).
} 
the women, but refused the plaintiffs to represent black men and accepted the defendant's request to narrow the class to Black women only. ${ }^{26}$ Through these cases adjudicated by the courts in the U.S.A, it can be fairly assumed that the discrimination law jurisprudence in the U.S.A, has not been able to accommodate intersectional claims, especially those where the identity of race and sex intersect.

\section{3(ii) United Kingdom (UK)}

The United Kingdom discrimination law jurisprudence has developed through legislations like the Race Relations Act, 1976, Sex Discrimination Act, 1975, Equality Act, 2010 and Employment Equality Regulations. ${ }^{27}$ However, it can be observed that even after having a spectrum of legislations regarding discrimination, all of them perpetrate a 'single axis' model. None of the legislations make any provision for a multiple discrimination claim, let alone for an intersectional one. According to the Equality Act, 2010 a discriminative act is prohibited against statutorily defined protected characteristics 28 like age, disability, gender reassignment, etc. ${ }^{29}$ The 'protected characteristics' are independent and considered mutually exclusive. However, in 2009, the Government of UK published a discussion paper, assessing the inherent faults in the equality legislations and proposed recognition to an intersectional claim to be included in the Equality Bill (now, Equality Act, 2010). The prospective Section 14 contains provisions for 'combined discrimination' on dual 'protected

\footnotetext{
26 Crenshaw, supra at 148.

27 Government Equalities Office, Equality Act 2010: guidance, GOV.UK, (Nov. 21, 2017, 12:25 AM),https://www.gov.uk/guidance/equality-act2010-guidance.

28 United Kingdom Equality Act, § 13, (2010) -Direct discrimination (1) A person (A) discriminates against another (B) if, because of a protected characteristic, A treats B less favorably than A treats or would treat others. ${ }_{29}$ United Kingdom Equality Act, § 4, (2010) -The following characteristics are protected characteristics - age; disability; gender reassignment; marriage and civil partnership; pregnancy and maternity; race; religion or belief; sex; sexual orientation.
} 
characteristics' ${ }^{30}$ Nonetheless, the incumbent government declined to bring this provision into force and while there is recognition in policymaking that intersectional discrimination exists and is not addressed adequately by the existing law, it has not led to changes in the law. ${ }^{31}$ Yet, courts have not been so reluctant in addressing issues relating to multiple ground discriminations.

In Bahl v. The Law Society and Others ${ }^{32}$, an Employment Tribunal (ET) found that Dr. Bahl was subjected to discrimination based on race and sex at the same time. But, the decision was overturned by the Employment Appellate Tribunal (EAT) and the Court of Appeal, on the basis that the Tribunal had failed to adjudicate upon the claims independently.

This strict sense of interpretation of discrimination laws came under consideration in $O^{\prime}$ Reilly $v . B B C$ and another. ${ }^{33}$ Ms. O'Reilly alleged that she had been removed from the program due to discrimination on the combination of grounds of age and sex. BBC argued that if the Employment Tribunal were to find that the reason for removing Ms. O'Reilly was truly due to the combination of her age and sex, this would not amount to unlawful discrimination, because combined discrimination is not prohibited under the pre-Equality Act legislation. The ET found this argument to be flawed, because the particular protected characteristic need not be the sole or even the principal reason why a person suffers detrimental treatment, in order for a claim on that ground to

30 United Kingdom Equality Act, § 14, (2010) -Combined discrimination: dual characteristics (1) A person (A) discriminates against another (B) if, because of a combination of two relevant protected characteristics, A treats B less favorably than A treats or would treat a person who does not share either of those characteristics.

31 Executive Director, Equality Bill: Assessing the impact of a multiple discrimination provision, EQUAL RIGHTS TRUST, 3.5 (Oct. 25, 2017, 9:00 AM) http:// www.equalrightstrust.org/ ertdocumentbank/ The\% 20 Equal\%20Rights\%20Trust \%20Multiple\%20discrimination \%20Consultatio $\mathrm{n} \%$ 20Response.pdf.

32 Bahl v. The Law Society and Others, [2004] IRLR 799.

33 O'Reilly v. BBC and another, Case no. 2200423/2010, 10th January 2011 (UK). 
succeed. If a claimant is able to show that her sex is a part of the reason for detrimental treatment, she will succeed in a sex discrimination claim. If she proves that age was a part of the reason, she will succeed in her age discrimination claim. Both claims can succeed, taken separately, which will lead to a conclusion that the treatment was both on the grounds of age and sex - thus allowing a tribunal to make a finding of discrimination on multiple grounds. Though this case proved to be a watershed judgment for inclusion of a multiple ground discrimination claim, it can be argued that even this case could not reproduce the essence of intersectionality as both claims are looked at as independent claims, capable of being proved without the help of the other. ${ }^{34}$

It has been argued that such a distinction is only academic in nature and till the time judgments are making provisions for multiple ground claims, there is no practical significance of such discussions. 35

\section{3(iii) India}

Article $15^{36}$ of the Constitution of India, along with various statutes enacted by the Parliament, is the source of discrimination law jurisprudence in India. For a purposive understanding of the jurisprudence underlying the aforementioned Article, an interpretation of the phrase 'on grounds only of' 37 as linking the basis of discrimination to the listed or constitutionally protected grounds, is required to be done. ${ }^{38}$

\footnotetext{
${ }^{34}$ Anna Beale et al; Equalities briefing six: Dual discrimination, CLOISTERS, (Oct. 26, 2017, 6:30 PM), https:// www.cloisters.com/ images/ easyblog _images/45/viewpoint-6---dual-discrimination.pdf. [Beale]

${ }^{35}$ Beale, supra at 3.

36 INDIAN CONST., Art 15, cl. 1.

37 INDIAN CONST., Art 15, cl. 1.

38 Shreya Atrey, Through the Looking Glass of Intersectionality: Making Sense of Indian Discrimination Jurisprudence under Article 15, 16 Equal Rights Review 160, 161 (2016). [Atrey]
} 
The meaning of 'on grounds only of' in Section 298(1) came to be considered by the Bombay High Court in Punjab v.Daulat Singh ${ }^{39}$. Lord Thankerton, writing for the majority held that:

[I]t is not a question of whether the impugned Act is based only on one or more of the grounds specified in Section 298(1), but whether its operation may result in a prohibition only on these grounds. The proper test as to whether there is a contravention of the sub-section is to ascertain the reaction of the impugned Act on the personal right conferred by the sub-section.

Thus, a reasonable interpretation of this case, perforce, suggests that the phrase 'on grounds only of' signifies the basis of discrimination to be on one or more grounds under Section 298(1). ${ }^{40}$

The abovementioned test, popularized as the 'result or effect' test, was upheld, subsequently, in Bombay v. Bombay Education Society ${ }^{41}$ case. The case involved restriction of admission to English speaking pupils viz. Anglo Indians of European descent in the English medium schools of Bombay, which was contended as a violation of Article 15 read with Article 29 of the Constitution of India. The Government, on behalf of the educational institution, claimed that the restriction enforced was not discrimination based only on ground of religion, race, caste, language or any of them "but on the ground that such denial will promote the advancement of the national language and facilitate the imparting of education through the medium of the pupil's mother tongue." 42

This object and purpose based justification of the government was denied by the Court as an incorrect test in the light of Daulat Singh, and the Court proceeded with applying Lord Thankerton's test in

\footnotetext{
39 State of Punjab v.Daulat Singh, (1946) 73 IA 59, (1946) FCR 1 (India). 402 H.M SEERVAI., CONSTITUTIONAL LAW OF INDIA, 558 (4th ed, 2001).

41 Bombay v. Bombay Education Society, (1955) 1 SCR 568, 581, 583-584.

${ }^{42} I d$. at 582.
} 
that "[w] hatever the object, the immediate ground and direct cause for the denial" dictates the inquiry. 43

In Mahadeb v.Dr BB Sen, ${ }^{44}$ Justice Mukharji opined that:

The word "only" in Article 15(1) is of great importance and significance which should not be missed. The impugned law must be shown to discriminate because of sex alone. If other factors in addition to sex come into play in making the discriminatory law, then such discrimination does not, in my judgment, come within the provision of Article 15(1) of the Constitution. ${ }^{45}$

Similarly, in Anjali Roy v. State of West Bengal, 46 the Calcutta High Court held:

What the Article forbids is discrimination and discrimination based solely on all or any of the grounds mentioned in the Article (...) the discrimination which is forbidden [in Article 15(1)] is only such discrimination as is based solely on the ground that a person belongs to a particular race or caste or professes a particular religion or was born at a particular place or is of a particular sex and on no other ground. ${ }^{47}$

Thus, we can observe that the discrimination law jurisprudence in India, developed around discrimination based on sex, coupled with other considerations mentioned under Article 15. Various other judgments of the courts in India have added to the understanding of prohibition of discrimination by a single axis model viz.

\footnotetext{
${ }^{43}$ Atrey, supra at 166.

${ }^{44}$ Mahadeb v. Dr BB Sen, AIR 1951 Cal 563. [Mahadeb]

${ }^{45}$ Mahadeb,supra at 28.

46 Anjali Roy v. State of West Bengal, AIR 1952 Cal 825.

${ }^{47} I d$ at 839 . 
Dattatraya Motiram More v. State of Bombay48, Government of Andhra Pradesh v. PB Vijaykumar49, Vijay Lakshmi v. Punjab University50, etc.

It is interesting to note that the logic of serving the interests of women through clause (3) of Article 15, comes heavily couched in the language of protectionism, viewing women as the weaker sex, thus, reinforcing the very stereotypes, discrimination is meant to combat. ${ }^{51}$ The continuous course of judgments adhering to the textual view of biological understanding of sex, as differed from gender, under Article 15(1) and unquestioned paternalistic protectionism of Article 15(3) 52 was interrupted, and rightfully so, by the decision in Anuj Garg v. Hotel Association of India ${ }^{53}$. The case was a constitutional challenge to an enactment which prohibited employment of woman in premises, where alcohol was consumed in public. The Supreme Court of India declared the provision as unconstitutional and quoted the decision of US Supreme Court in Frontiero $v$. Richardson ${ }^{54}$. Thus, this case changed the course of discussions around gender discrimination and protectionism, under the discrimination law jurisprudence for a short while. But, even today the justification of discrimination based on more than one ground is problematic, unsatisfactory, and in most cases, unrecognized.

Though the jurisprudence behind discrimination laws in India still struggles to accommodate multiple ground claims and intersectionality, the Anti-Discrimination and Equality Bill, 2016 introduced by Dr. Shashi Tharoor, Member of Parliament, tries to

48Dattatraya Motiram More v. State of Bombay, AIR 1953 Bom 311.

${ }^{49}$ Government of Andhra Pradesh v. PB Vijaykumar, AIR 1995 SC 1648.

${ }^{50}$ Vijay Lakshmi v. Punjab University, AIR 2003 SC 3331.

${ }^{51}$ Atrey, supra at170.

52 INDIAN CONST., Art 15, cl 3.

${ }^{53}$ Anuj Garg v. Hotel Association of India, (2008) 3 SCC 1.

${ }^{54}$ Frontiero v. Richardson, 411 U.S. 677, 93 S.Ct. 1764 . "There can be no doubt that our Nation has had a long and unfortunate history of sex discrimination. Traditionally, such discrimination was rationalized by an attitude of 'romantic paternalism' which, in practical effect, put women, not on a pedestal, but in a cage." 
incorporate this approach. ${ }^{55}$ Section 3 of this Bill has defined "Protected Characteristic" with a specific acknowledgement and recognition to a multiple ground claim. ${ }^{56}$ Section 1 (iii) provides for a provision of inclusion of a multiple ground claim and a true intersectional claim. Also, Section 4 of the same Bill defines "protected group" and the Illustration No. 2 gives an apt example of how the Bill seeks to include a multi-ground claims. ${ }^{57}$ Section 5 of the Bill defines "disadvantaged group" by giving an illustrative enumeration of such groups based on caste, race, sex, gender identity, pregnancy, sexual orientation, disability, linguistic identity, etc. Further, the same section also defines the "disadvantaged group" as a combination of any of the enumerated groups, which provisions a possible cross-over between the groups and can be a legitimate ground for an intersectional claim.

\section{4 Adjudication of Intersectionality Claims - India}

Predominantly, there have been two identities which have occupied prime positions in the narrative of feminist movements in the West, that is, gender and race/ethnic origin. ${ }^{58}$ Examples can be

55 Suhrith Parthasarathy, To be equal before the law, THE HINDU (21 Nov. 2017, 9:40 PM) http://www.thehindu.com/opinion/lead/To-beequal-before-the-law/article14479752.ece.

56 Anti-Discrimination and Equality Bill, § 3, Bill No. 289 of 2016, (2016) A "protected characteristic" in relation to a citizen of India means - (i) caste, race, ethnicity, descent, sex, gender identity, pregnancy, sexual orientation, religion and belief, tribe, disability, linguistic identity, HIV status, nationality, marital status, food preference, skin tone, place of residence, place of birth or age; or (ii) any other personal characteristic which, - (a) is either outside a person's effective control, or constitutes a fundamental choice, or both; and (b) defines at least one group that suffers or is in danger of suffering widespread and substantial disadvantage, when compared with other groups defined by the same characteristic; or (iii) a combination of any of the above.

57 Anti-Discrimination and Equality Bill, § 4, Bill No. 289 of 2016, (2016) Illustration No.2- Muslim women are a protected group defined by a combination of two protected characteristics: sex and religion.

58 Felice Batlan, Race, Gender, and, Feminist Legal Advocacy during the Long Civil Rights Movement, JOTWELL (26 Nov. 2017, 9:00 PM) 
taken of various European Nations which have separate bodies addressing such discriminations viz. former Commission of Racial Equality in Britain and the Sexuality Ombudsman in Sweden 59. However, across the world, the number of protected grounds from discrimination has dramatically increased, for instance, Article 15 of Indian Constitution includes place of birth, religion and caste, as additional grounds, for, they are very specific to discriminatory practices prevalent in India. Therefore, in European Union as well as other common law jurisdictions, there is a constant pressure towards not just addressing and adjudicating multiple grounds of discrimination, but also their interaction in the form of intersectionality in a single piece of legislation and by a single body. In India, the Constitution provides for a robust number of grounds of discrimination and protection from the State in Articles 14, 15 and 16. Under Article 32 and Article 226, in case of any violation of a fundamental right, the Supreme Court or High Court, respectively, can adjudicate the matter under their writ jurisdiction. But, there are various legislations laying special focus on caste based discrimination and untouchability, like Protection of Civil Rights Act, 1955, The Scheduled Castes and the Scheduled Tribes (Prevention of Atrocities) Act, 1989, etc. The plethora of legislations cast a duty on the State to prevent such discrimination, but only of the kind of discrimination that is provided for, in that specific Act.

Intersectionality has not been recognized in India as a valid form of discrimination, as explained above. The only recourse for an intersectional claim is to file a writ petition at the High Court or the Supreme Court, seeking redress under Article 226 or 32 for a violation of the rights mentioned under Article 15 or 16, as the case maybe. However, the aforementioned judgments of the Indian Courts show that a multiple-ground claim, let alone intersectional ones, cannot be admitted under the Right to Equality regime in the Constitution of India, and claimants, for all intent and purposes, have been rendered remediless. The Anti-Discrimination and

https://legalhist.jotwell.com/race-gender-and-feminist-legal-advocacyduring-the-long-civil-rights-movement/.

59 European Commission, A Comparative Analysis Of Non-Discrimination Law In Europe,EUROPA,(Nov. 21 2017, 12:45 AM)http:// ec.europa.eu/ justice/discrimination/files/comparative_analysis_nd_2015.pdf. 
Equality Bill, 2016, as mentioned earlier, provides a scheme for institutionalization of Intersectionality. Apart from including intersectionality in the definition of 'Protected Characteristic' and 'Protected Group', it also provides for establishment of a Central Equality Commission, which shall have powers to eliminate discrimination, promotion of awareness, etc. and also, in consultation with State Equality Commission, issue guidelines for protection from discrimination. Both the Commissions have judicial powers with State Commission having original jurisdiction. The Bill also provides for various kinds of remedies available against intersectional discrimination. The High Court has been vested with the appellate jurisdiction in this Bill.60 This Bill alone, provides for a successful intersectional claim which can be adjudicated upon by the Equality Commissions, apart from the constitutional remedies under Article 32 and 226, which, due to plethora of precedents on multiple ground claims, have been made redundant. The establishment of this Commission brings several kinds of discriminations under a single legislation and before one body, thus ensuring ease in access of justice, speedy procedure, and clarity. However, the Bill is still pending in the Parliament.

\section{Substantive Equality beyond Intersectionality}

Before understanding the need to look beyond just the intersectionality theory, to bring home the idea of 'substantive equality', it becomes imperative to understand the phraseology behind 'substantive equality' and how it is different from 'formal equality'. From there we can discuss how to achieve substantive equality, which is a much wider and holistic ideology towards welfare legislations and principles governing adjudication.

\section{1 Formal Equality versus Substantive Equality}

The most widespread and replicated understanding of equality comes from Aristotle's dictum that equality meant "things that are

\footnotetext{
${ }^{60}$ Anti-Discrimination And Equality Bill, § 17, § 23, § 24, § 25, § 31, § 32, § 33, Bill No. 289 of 2016, (2016).
} 
alike should be treated alike". ${ }^{61}$ Formal Equality, essentially, promotes individualistic justice, which requires consistent and equal treatment. Traditionally it has formed the basis of 'direct discrimination' on guarantee in the UK, equal protection in the US Constitution and the Right to Equality in the Indian Constitution. It supports the position that personal traits or characteristics should be viewed as irrelevant in determining whether they have a right to some social benefit or not. The most blatant drawback of such approach is that it requires comparison, which forms the idea of a 'universal man' which can neglect the diversity in society. ${ }^{62}$

The approach of formal equality in case of discrimination law, therefore, becomes color blind rather than being color conscious. Therefore this approach, and its juxtaposition on the modern society, becomes overly simplistic.

In Withler v. Canada63, substantive equality has been explained as:

Substantive equality, unlike formal equality, rejects the mere presence or absence of difference as an answer to differential treatment. It insists on going behind the facade of similarities and differences. It asks not only what characteristics the different treatment is predicated upon, but also whether those characteristics are relevant considerations under the circumstances. The focus of the inquiry is on the actual impact of the impugned law, taking full account of social, political, economic and historical factors concerning the group. ${ }^{64}$

\footnotetext{
${ }^{61}$ ARISTOTLE, ETHICA NICOMACHEA, 112-117, 1131a-1131b, (Ackrill, J. L. and Urmson J. O. eds, Oxford University Press), (1980).

62The Ideas of Equality and Non-Discrimination: Formal and Substantive Equality, EQUAL RIGHTS TRUST,(Nov. 21 2017, 12:47 AM) http:/ / www.equalrightstrust.org/ertdocumentbank/The \%20Ideas $\% 20$ of $\%$ 20Equality $\% 20$ and $\% 20$ Nondiscrimination,\%20Formal\%20and\%20Substantive\%20Equality.pdf. ${ }^{63}$ Withler v. Canada, 2011 SCC 12 (Canada).

${ }^{64}$ Id at 39.
} 
As Nina A. Kohn highlights, the doctrine of formal equality has been severely criticized on the grounds that the pre-existing disadvantages of groups in the society radically differ and repeatedly applying consistent rules in such a scenario produces unequal results. 65

The contrast between formal and substantive equality as standards can be further illustrated by considering the law of prostitution. ${ }^{66} \mathrm{~A}$ substantive sex equality approach would decriminalize people sold in prostitution and strongly criminalize those who buy and sell them. ${ }^{67}$ Almost all those who would be prosecuted under such a scheme, as with rape laws, would predictably be men, either as sellers or buyers, which is substantively a male dominant behavior. Anyone bought or sold for sex would not be prosecuted, as they are substantively in a female or subordinate position, regardless of their sex. This gives a brief understanding about the need to consciously move towards substantive equality, while formulating laws to effectively address discrimination.

\section{2 The problem with Intersectionality Theory}

The most perceptible problem that could be extrapolated is the problem of inequality within intersectionality. Susanne Knudsen argues that the multiple inequality markers may make way for a serious problem, that is, one category may be considered as more significant than others. She uses Crenshaw's metaphor of a "crosssection", and states that "ethnicity may be chosen in favor of gender as the one road chosen, while the other road is left behind." 68 Knudsen then talks about "competing

${ }^{65}$ Nina A. Kohn, Vulnerability Theory and the Role of Government, 26 Yale J.L. \& Feminism 1, 2-3 (2014). [Kohn]

${ }^{66}$ Catharine A. MacKinnon, Substantive Equality: A Perspective, 6 Minn. L. $\operatorname{Rev} 1,1-27$ (2012).

67 Catharine A. MacKinnon, Trafficking, Prostitution, and Inequality, 46 HARV. C.R.-C.L. L. REV. 271, 301-04 (2011).

68 Susanne Knudsen, Intersectionality - A Theoretical Inspiration in the Analysis of Minority Cultures and Identities in Textbooks, SCIELO COLUMBIA, 63 (Oct. 25, 2017, 2:30 PM), www.caen.iufm.fr/ colloque_iartem/pdf/knudsen.pdf+intersectionality+theory\&hl=en\&ct $=\mathrm{cl}$ $\mathrm{nk} \& \mathrm{~cd}=3 \& \mathrm{client}=$ firef ox. 
intersectionalities", where these are categorized on a hierarchybasis and gives an example of the 1970's America, where class and race had gained more significance than gender, which toppled later, and brought race and gender again back to the forefront. For instance, transgender people of color face extraordinary risks of discrimination ${ }^{69}$, yet, are too often ignored in mainstream discourses involving gender, race and sexuality. The author disagrees with Knudsen on some of the inherent flaws in the theory.

These flaws cannot be used to totally negate the voice that intersectionality gives to plurality of experiences, which work towards attainment of substantive equality. Though it can be safely accepted that recognition of intersectional discrimination cannot be a panacea for all discrimination law and policy failures, there are various other reforms that need to be addressed and accommodated to strive for substantive equality which might go beyond the purview of this Article. The author would introduce and make preliminary suggestions on Martha Fineman's Vulnerability Theory, which makes a great argument for expansive social welfare laws and how vulnerability fits in the design of discrimination law.

\section{Vulnerability Theory: A Post-Identity Approach}

This theory stems from the contentions around the role of the State as the allocator of the resources among its subjects. The questions aren't raised just on how the allocation must be done but also on the extent of such allocation and whether the State is under any obligation..$^{70}$ Such concerns developed only after there was a shift in the policy-making from Laissez Faire to Welfare State. Though the job of redistribution of resources through taxation and social welfare programs was accepted, it was done only as a choice, not as

69 Transgender Europe's, Trans Murder Monitoring Project, TGEU, (Oct. 26, 2017, 4:00 AM) http://www.transrespect-transphobia.org/en_US/tvtproject/tmm-results/idahot-2015.htm. - reports that 1,701 trans-people have been murdered globally between 2008 and 2014.

${ }^{70} \mathrm{Kohn}$, supra at2. 
an obligation. ${ }^{71}$ The only job performed by the government, as discussed earlier, was to prevent unjust discrimination and ensure equal treatment of all, in the eyes of law.

Martha Fineman, while introducing this theory for the first time ${ }^{72}$ starts the discussion from the question of how the resources must be allocated to achieve substantive equality.

"It proposes that vulnerability is inherent to the human condition, and that governments therefore have a responsibility to respond affirmatively to that vulnerability by ensuring that all people have equal access to the societal institutions." 73

The theory aims to replace the liberal subject of State with a vulnerable subject. While a liberal subject is a competent social actor capable of simultaneous multiple identities, a vulnerable subject is anchored by dependency and absence of capacity ${ }^{74}$ which, according to her, is all-pervading. It, quintessentially, delves into the concept of individual vulnerability, which includes harms of past, speculations about future, and immediate harm. ${ }^{75}$

This approach moves beyond the societal identities of an individual. Fineman puts forward this thought in the following fashion:

A vulnerability analysis greatly magnifies state responsibility for the institutions and structures the state constructs and utilizes. Vulnerability analysis demands that the state give equal regard to the shared vulnerability of all individuals, transcending the old identity categories as a limitation on the recognition that the state has a vital role to play in protection against discrimination. ${ }^{76}$

${ }^{71}$ Katrina Robin West, The Constitution, and the Legal Question Doctrine, 81 CHI.-KENT L. REV. 1127, 1129-30 (2006).

${ }^{72}$ Fineman, supra at 34.

${ }^{73}$ Kohn, supra at 3.

${ }^{74}$ Fineman, supra at 12.

${ }^{75}$ Idat 12.

${ }^{76} I d$ at 20. 
Therefore, according to her, the erstwhile application of liberal subject in welfare legislations addressing social disparities and discrimination, fails to justify differential allocation of privileges produced by social institutions. The current functioning model, as in the US, mires us in a battle of identity politics, where every gain by a minority individual, becomes a justification for abandoning the pursuit of substantive equality. ${ }^{77}$

\section{1 Difference between Intersectionality and Vulnerability}

At the outset, the author wishes to state that this distinction is purely academic in nature. Though intersectionality has been an important tool in the hands of feminists, this article specifically deals with its reception and accommodation by Courts adjudicating such discrimination claims. Vulnerability theory was developed to achieve a more responsive State and an egalitarian society. Therefore, the former functions on recognition of interplay of identities during instances of discrimination and their adjudication by Courts, and the latter primarily functions on the policy decisions and distribution of resources on the basis of universally inherent vulnerabilities, that sets to go beyond identities. However, vulnerability theory also falls prey to and succumbs to the identity politics, which it initially tends to surpass.

A legitimate question that arises is that when applied to the same situation, these theories tend to clash and conflict with each other, as one is based on identity and the other transcends beyond identities. The author proposes that these theories can be reconciled, in the sense as mentioned above i.e. intersectionality should be used by courts to admit claims of discrimination, where more than one identity is at play and Vulnerability should be used as a broad principle underlying policies of the State, to address various vulnerabilities like old age, which are universally present and beyond specific "protected" identities or characteristics, like those mentioned in Article 15 viz. race, caste, gender, place of birth, religion, etc.

77Idat 20. 


\section{2 Criticism of Vulnerability Theory}

A vulnerability analysis magnifies a State's responsibility. But, even this approach has been marred by some significant flaws and has been, therefore, subjected to criticism by various scholars. First, much of Fineman's analysis is at an abstract level with no contemporary examples. Second, when Fineman tries to give a policy change in one of her works ${ }^{78}$, she resorts to an identity approach by identifying vulnerability, within the elderly population. ${ }^{79}$ Therefore, she tends to succumb to the same identity politics with which she began her analysis and later criticizes the same. Third, in her earlier work ${ }^{80}$ she is very skeptical of the value of autonomy for citizens. Therefore, she suggests reforms in form of overly-paternalistic laws, which range from voiding certain transactions entered into by older people, to treating the legal capacity of older adults as less absolute than that of younger adults. ${ }^{81}$ Such laws prove to be a deterrent towards substantive equality in the long run. There have been various instances where, even in India, paternalistic laws accompanied by a protectionist interpretation by Courts, have led to an atmosphere of depressed autonomy, especially, that of women in the light of discrimination law jurisprudence.

In Air India v. Nergesh Meerza 82, the Supreme Court while discussing the Air India Employees Service Regulations on retirement of an air hostess from service on grounds of marriage, first pregnancy, and attainment of age of 35 years, upheld the condition of termination upon marriage within four years of service. This was done on the basis of family planning, improving health and maturity of the employee with growing age and hence

78 Martha A. Fineman, "Elderly" as Vulnerable: Rethinking the Nature of Individual and Societal Responsibility, 20 ELDER L.J. 71, 84 (2012).

79 Kohn, supra at 11.

80 MARTHA ALBERTSON FINEMAN, THE AUTONOMY MYTH: A THEORY OF DEPENDENCY, 20-30 (The New Press 2004).

${ }^{81}$ Kohn, supra at 8.

${ }^{82}$ Air India v. NergeshMeerza, 1982 SCR (1) 438. 
ensuring the success of marriage, as well as the economic costs of training the crew. .3

The fact that the Court yields to arguments such as allowing female air hostesses to mature, by delaying their marriage prospects to ensure successful marriages is based on a patronizing view of sex and gender and an appropriation of women's personal autonomy. It views women as incapable and in need of direction from the State. ${ }^{84}$

Therefore, this case clearly shows the downside of a protectionist approach towards equality, and how, in the garb of a paternalistic legislation or provision, substantive equality can be compromised by non-recognition of discrimination. Though different in terms of object of inquiry (Fineman's analysis being on older adults, and Nergesh Meerza's case on the rights of women), both show a rather disappointing consequence of a paternalistic approach towards law-making.

Nevertheless, it can be safely stated that it is a probable alternative to the prevalent formal equality paradigm. But it needs to be kept in mind that while Vulnerability Theory can be employed to set up broad policies, unlike intersectionality, it cannot be helpful in choosing particular policies for achieving substantive equality. The tragedy of this theory is that if vulnerability is taken as an inherent characteristic of each individual and not defined on case by case basis, even this theory will simply be reduced into an identity based approach.

\section{Conclusion}

The purpose of this article has been to provide a prefatory understanding of the complex and layered concept of intersectionality. Starting from the birth of the concept, till its current manifestation, and its condition in various leading jurisdictions of the world, viz. US, UK and India; the author has analyzed the extent and degree of adaption, and its possible

${ }^{83}$ Id. at 19.

${ }^{84}$ Atrey, supra at $173-74$. 
contribution to substantive equality. While Intersectionality, quintessentially, is more sophisticated and complex than additive discrimination, the tragedy is that major jurisdictions are yet to move beyond the single-axis model to accommodate an additive claim, let alone an intersectional one. But, even intersectionality is not insulated from flaws, for example, it has a potential to create hierarchies amongst the identities, interplaying at the same time. Therefore, as expressed earlier it could not be a sole instrument to achieve the lofty ideals of substantive equality. Vulnerability theory comes across as a viable approach aimed towards taking the conversation beyond identities, and placing the focus on the innate vulnerabilities that are universally inherent in every individual. However, the theory has failed on account of its simplistic and paternalistic attitude, and over-protectionist approach. While Intersectionality can be a significant ideological and legislative shift that can be implemented by Courts, which can voice concerns of various marginalized communities, vulnerability theory can be a tool in setting broad policies concerning allocation and distribution of resources. Both can work simultaneously on different fronts, as each can be harmonized to fill the theoretical gaps left by the other. 